\title{
Síndrome de Burnout em Profissionais de Enfermagem
}

\author{
Burnout Syndrome in Nursing Professionals \\ Síndrome de Burnout en Profesionales de Enfermeíra
}

Recebido: 17/09/2021 | Revisado: 21/09/2021 | Aceito: 23/09/2021 | Publicado: 01/10/2021

Marlucia Sousa da Silva
ORCID: https://orcid.org/0000-0002-9819-379X
Universidade de Palmas, Brasil
E-mail: marluciass@ @mail.com
Tamyze Bezerra Gomes
Uamyiversidade de Palmas, Brasil
E-mail: tamyzegomes@gmail.com
ORCID: https://orcid.org/000-002-3698-158
Raylton Aparecido Nascimento Silva
ORCID: https://orcid.org/0000-0003-3832-7685
Universidade Federal de Santa Maria, Brasil
E-mail: rayltonaparecido@gmail.com
Naiara Mesquita Almeida
ORCID: https://orcid.org/0000-0002-9952-2751
Universidade Federal do Tocantins, Brasil
E-mail: nnaiaramesquita@ @mail.com
Tallyta Barros Ribeiro
ORCID: https://orcid.org/0000-0001-5203-2731
Universidade Federal do Tocantins, Brasil
E-mail: tallytaribeiro@ @ail.uft.edu.br
Thiago Oliveira Sabino de Lima
ORCID: https://orcid.org/0000-0003-2677-9481
Universidade de Palmas, Brasil
E-mail: thiagosabino@ uft.edu.br
Carlos Mendes Rosa
OR.

\section{Resumo}

Neste trabalho temos como objetivo analisar a síndrome de Burnout em profissionais de enfermagem verificando como que esta acarreta em prejuízo ao profissional de enfermagem. A partir disso foi realizada uma pesquisa de revisão de literatura, sendo utilizados como base de estudo as bases de dados eletrônicos: Scielo, Bireme e Google acadêmico. Como resultados, verificamos que a síndrome de Burnout tem acometido cada vez mais profissionais da enfermagem devido, principalmente ao contexto no qual ele está inserido, gerando altos índices de absenteísmo, acidentes, doenças, conflitos, abandono e desinteresse, verificados em todos os níveis do processo de trabalho, dessa forma, cabe o estudo de novas pesquisas, principalmente na atual conjuntura da pandemia da COVID-19 em que perpassa o mundo, sendo importante investigar como os profissionais de enfermagem tem sido afetados psicologicamente tanto pelo o excesso de trabalho quanto pela tensão de exposição pessoal e de seus familiares ou ainda pela a impotência diante do enfrentamento da doença.

Palavras-chave: Síndrome de Burnout; Enfermagem; Profissionais.

\section{Abstract}

In this work, we aim to analyze the Burnout syndrome in nursing professionals, verifying how it harms the nursing professional. From this, a literature review research was carried out, using as a base of study the electronic databases: Scielo, Bireme and Academic Google. As a result, we found that Burnout syndrome has increasingly affected nursing professionals, mainly due to the context in which it is inserted, generating high rates of absenteeism, accidents, illnesses, conflicts, abandonment and disinterest, verified at all levels of the work process, therefore, it is necessary to study further research, especially in the current context of the COVID-19 pandemic in which it pervades the world, and it is important to investigate how nursing professionals have been psychologically affected both by overwork and by the tension of personal exposure and that of their family members or even impotence in the face of the disease.

Keywords: Burnout syndrome; Nursing; Professionals. 


\section{Resumen}

En este trabajo, pretendemos analizar el síndrome de Burnout en profesionales de enfermería, verificando cómo perjudica al profesional de enfermería. A partir de esto, se realizó una investigación de revisión de la literatura, utilizando como base de estudio las bases de datos electrónicas: Scielo, Bireme y Academic Google. Como resultado, encontramos que el síndrome Burnout ha afectado cada vez más a los profesionales de enfermería, principalmente por el contexto en el que se inserta, generando altas tasas de absentismo, accidentes, enfermedades, conflictos, abandono y desinterés, comprobados en todos los niveles del proceso laboral. Por ello, es necesario profundizar en la investigación, especialmente en el contexto actual de la pandemia de COVID-19 en el que invade el mundo, y es importante investigar cómo los profesionales de enfermería se han visto afectados psicológicamente tanto por el exceso de trabajo como por la tensión de exposición personal y de sus familiares o incluso impotencia ante la enfermedad.

Palabras clave: Síndrome de Burnout; Enfermería; Profesionales.

\section{Introdução}

A Síndrome de Burnout (SB) é uma doença definida como o esgotamento profissional decorrente da tensão emocional crônica no trabalho e tem como características principais a Exaustão Emocional, caracterizada como a fadiga geral; a despersonalização, que é o desenvolvimento de sentimentos de negatividade; e a baixa realização profissional, ou seja, a insatisfação com o trabalho (Santos, et al 2009).

Segundo os estudos de Moreira, et al (2009) a síndrome é de origem inglesa que etimologicamente significa "o ato de queimar-se / combustão", caracterizando um processo que ocorre gradualmente sendo primeiramente descrito pelo psiquiatra Freudenberger, em 1974. Já Silva (2010) afirma que os primeiros casos foram descritos nos Estados Unidos da América. Todavia, os dois estudos concordam que o termo surgiu na década de 70 e acontece quando o profissional não consegue mais lidar com o estresse ocasionado pelo trabalho.

De acordo com Menezes (2015), a síndrome de Burnout é derivada do esgotamento profissional, devendo ser estudada dentro da abordagem de suas três características principais: exaustão emocional, quando o profissional apresenta sentimentos de desgaste emocional e esvaziamento afetivo; despersonalização, quando ele demostra reação negativa, insensibilidade ou afastamento excessivo do público que deveria receber os seus serviços e/ou cuidados; a diminuição do envolvimento pessoal no trabalho, que é quando o profissional apresenta um sentimento de diminuição de competência e de sucesso no trabalho, sendo que esse diagnóstico só pode ser dado por um especialista médico psiquiatra.

De igual modo, a síndrome está vinculada ao trabalho causada por repetitivas pressões emocionais sofridas pelos profissionais ao longo do tempo. Ela afeta, principalmente, profissionais que atuam na educação, saúde, e segurança, tais como profissionais da enfermagem, entre outros, ligados a atividades que exigem elevado estresse emocional. Esse estresse ocupacional pode gerar impacto para o próprio trabalho do indivíduo e para todas as outras áreas, na medida em que está relacionado a todas elas, afetando diretamente sua qualidade de vida (Menezes, 2015).

Assim, o objetivo geral deste artigo foi analisar a síndrome de Burnout em profissionais de enfermagem. Para tanto, este trabalho tem sua importância na possibilidade de agregação de conhecimentos em enfermagem que pode propiciar produção de saber no campo pessoal, profissional e social, a fim de desenvolver ações que viabilizem a melhoria do processo de trabalho, bem como da qualidade de vida desses profissionais em sua prática laboral, a partir da análise da síndrome de Burnout em profissionais de enfermagem. A metodologia utilizada foi um uma pesquisa bibliográfica, realizada por meio de leitura de materiais disponibilizados em sites eletrônicos, destacando-se: Scielo, Bireme, Google acadêmico, dentre outros.

Desse modo, o interesse em estudar o assunto surgiu da importância em compreender as dimensões da saúde do profissional da enfermagem na contemporaneidade, pois cada dia as demandas aumentam em torno de uma sociedade cada vez mais estressada e o ambiente de trabalho tem sido reflexo dessa rotina social, sendo a área da saúde um processo de trabalho extremamente estressante porque lida com vidas (Santos, et al, 2009). 
A doença acomete o profissional de enfermagem de modo individual, prejudicando a sua relação com o trabalho e com a equipe, atrapalhando seu desempenho profissional e refletindo em prejuízos para a instituição que pode estender-se para o paciente assistido. A patologia é causada por um processo que se dá em resposta ao estresse emocional e interpessoal relativo ao trabalho, com origem nas relações sociais complexas que envolvem afetivamente profissionais e usuários de um serviço (Nascimento, 2013).

Moreira, et al (2009) apontam que o estresse na enfermagem não é prejudicial apenas ao profissional, mas, principalmente, ao contexto no qual ele está inserido, gerando altos índices de absenteísmo, acidentes, doenças, conflitos, abandono e desinteresse, verificados em todos os níveis do processo de trabalho, afetando desde o profissional, até os pacientes atendidos.

\section{Revisão Bibliográfica}

O processo histórico da Síndrome de Burnout denota o surgimento desta na década de 70, na Inglaterra e Estados Unidos da América, pois Moreira, et al, (2009) mencionam que o termo foi primeiramente descrito pelo psiquiatra Freudenberger, em 1974, na Inglaterra, enquanto Silva (2010) afirma que os primeiros casos foram descritos nos Estados Unidos. Todavia, os dois estudos convergem para a concepção de que a síndrome acontece quando o profissional não consegue mais lidar com o estresse ocasionado pelo trabalho em busca de resposta ao processo de deterioração, nos cuidados e atenção profissional aos trabalhadores de uma organização. Assim, ela foi definida como esgotamento profissional, uma síndrome psicológica decorrente da tensão emocional crônica no trabalho.

Os estudos de Silva (2010) ainda apontam que Freudenberger começou a falar em Burnout em 1974, assegurando que é uma doença advinda da decorrência de esgotamento, decepção e perda de interesse pela atividade de trabalho que surge nas profissões que trabalham em contato direto com pessoas. Kovaleski e Bressan (2012), por sua vez trazem em seus estudos que Burnout é uma síndrome que atinge trabalhadores em diversas profissões. É um problema que afeta, principalmente, os trabalhadores encarregados de cuidar de outros, como profissionais da área da educação, saúde, policiais e agentes penitenciários, entre outros, das quais são profissões que possuem intensos e frequentes contatos diretos com as pessoas.

É uma experiência que gera sentimentos e atitudes negativas com seu trabalho, podendo gerar desprazer, desgaste, perda do empenho. Suas consequências podem ser o absenteísmo, abandono do emprego e baixa produtividade. França e Ferrari (2011) apontam que os estudos iniciais sobre a investigação da Síndrome de Burnout em enfermeiros mostraram que a doença estava diretamente vinculada com a quantidade de tempo que os enfermeiros passam com os doentes, levando em consideração a intensidade das exigências emocionais destes e com o cuidar de doentes com mau prognóstico.

Nos estudos mais recentes é mostrado que o Burnout está associado a fatores relacionados com o trabalho, tais como sobrecarga de trabalho, falta de suporte, conflitos interpessoais, contato com a morte e preparação inadequada. Carlos e Gadelha (2011) afirmam que a Síndrome de Burnout afeta enfermeiros e profissionais de saúde de todo o mundo, em diversos conjuntos de trabalho, levando-os a desenvolver sentimentos de frieza, frustração, e indiferença em relação às necessidades e ao sofrimento dos doentes. Havendo assim, necessidades de desenvolver programas de prevenção e tratamento.

Logo, a Síndrome de Burnout acomete o profissional de enfermagem de modo individual, prejudicando a sua relação com o trabalho e com a equipe, atrapalhando seu desempenho profissional, e refletindo em prejuízos para a instituição, que pode estender-se para o paciente assistido. A patologia é causada por um processo que se dá em resposta ao estresse emocional e interpessoal relativo ao trabalho, com origem nas relações sociais complexas, que envolvem afetivamente profissionais e usuários de um serviço (Nascimento, 2013).

Desse modo, além de acarretar prejuízos ao profissional porque ele perde o interesse pelo labor, acomete absenteísmo ao trabalho, ele também acarreta prejuízo ao serviço, desatendimento, conflitos nas relações interpessoais, tanto com os 
colegas, quanto aos pacientes e familiares, podendo gerar até acidentes de trabalho afetando diretamente a vida e a saúde das pessoas assistidas, segundo os estudos de Moreira, et al (2009).

De igual modo, Moreira, et al (2009) diz que a Síndrome de Burnout (SB) atrapalha as relações familiares, deixando os indivíduos insatisfeitos e até evoluir para quadros psicológicos e psiquiátricos, bem como outras patologias como: hipertensão, diabetes, obesidade, ansiedade, dentre outras, de afeta diretamente a vida e a qualidade de vida desses profissionais.

\subsection{A Síndrome de Burnout e a qualidade de vida dos profissionais de enfermagem}

Menezes (2015) afirma que o estresse ocupacional vivido pelo profissional de enfermagem pode gerar impacto para o próprio trabalho do indivíduo e para todas as outras áreas, na medida em que está relacionado a todas elas, afetando diretamente sua qualidade de vida desses profissionais.

Os estudos de Moreira, et al (2009) apontam que o estresse na enfermagem afeta a qualidade de vida dos profissionais de enfermagem porque não é prejudicial apenas ao profissional, mas principalmente ao contexto no qual ele está inserido, gerando altos índices de absenteísmo, acidentes, doenças, conflitos, abandono e desinteresse, verificados em todos os níveis do processo de trabalho, afetando desde o profissional, até os pacientes atendidos.

Kovaleski e Bressan (2012) afirmam que a qualidade de vida dos trabalhadores da saúde encontra-se diretamente relacionado aos diferentes estressores ocupacionais. Entre os vários fatores de estresse ocupacionais, podemos citar a carência de profissionais ou indivíduos capacitados, as prolongadas jornadas de trabalho, a exposição do profissional a riscos químicos e físicos, a falta de reconhecimento profissional assim como o contato constante com o sofrimento, a dor e até mesmo a morte. Considerando estes fatores, os trabalhadores da saúde devem-se atentar com sua saúde mental e emocional mais que os profissionais de outras áreas.

\subsection{Ações que podem prevenir e tratar a Síndrome de Burnout em profissionais de enfermagem}

Devido a síndrome de Burnout ser derivada do esgotamento profissional, devemos estuda-la e desenvolver ações que possam prevenir a doença, dentro das três dimensões: Diminuir a exaustão emocional: quando o profissional apresenta sentimentos de desgaste emocional e esvaziamento afetivo Despersonalização: quando ele demostra reação negativa, insensibilidade ou afastamento excessivo do público que deveria receber os seus serviços e/ou cuidados; Diminuição do envolvimento pessoal no trabalho: quando o profissional apresenta um sentimento de diminuição de competência e de sucesso no trabalho.

Por conseguinte, devem-se desenvolver ações de diagnóstico e tratamento, como: Diagnóstico; Terapias; Tratamento. Os profissionais de enfermagem e da saúde em geral requerem conhecimento técnico cientifico voltado para o cuidado humano e holístico, além dos profissionais necessitarem de várias habilidades: cognitivas, interpessoais e psicomotoras aliadas ao fundamento teórico. Sendo assim, hoje, a enfermagem, por exemplo, é considerado um componente vital e indispensável do serviço de assistência médica (França \& Ferrari, 2011).

A exigência de conhecimentos técnico-científico dos profissionais de enfermagem tem sido cada vez mais exigida. Em compensação, é oferecido baixos salários e sobrecarga de tarefas para esses trabalhadores. Dessa forma fica visível de ser observado no ambiente de trabalho, alterações psíquicas que levam a um estado de exaustão emocional, perda de interesse pelas pessoas que teriam de ajudar; e, finalmente, baixo rendimento profissional e pessoal. No ambiente de trabalho, as situações indutoras do estresse, são cada vez mais crescentes (França \& Ferrari, 2011). 


\section{Metodologia}

Conforme os estudos de Moreira (2009), esse estudo foi realizado como uma pesquisa bibliográfica que foi realizada por meio de leitura de materiais disponibilizados em sites eletrônicos, destacando-se: SCIELO e BIREME. Os artigos foram selecionados por meio da leitura dos títulos, resumo e palavras-chave dos artigos, usando como parâmetro para a pesquisa os critérios de inclusão: tradução em português; publicados no período de 2006 a 2019; material elaborado e publicado dentro do tema em estudo, pesquisados pelos descritores "Síndrome de Burnout"; "Enfermagem"; e "Qualidade de vida".

A seleção do material bibliográfico ainda contou com a parte de exclusão de material que não se apresentou adequado ao estudo, sendo desconsiderados os artigos com os seguintes critérios de exclusão: publicados no período anterior ao ano de 2006; publicados em língua estrangeira e sem tradução para o português brasileiro; materiais incompletos e/ou fora do tema de estudo.

A análise foi feita pelo ano de publicação e tema, bem como nos estudos que apresentam índices que representam sinais positivos da doença, dentro de uma abordagem qualitativa, sendo que essa análise se dará por meio de leitura integral dos artigos incluídos, com posterior elaboração de uma planilha que trouxe os seguintes dados coletados a partir dos artigos analisados: objetivo do estudo; metodologia; e resultados alcançados. Após essa análise foi feita uma análise comparativa entre os artigos selecionados, no sentido de apresentar uma revisão de literatura sobre a síndrome de Burnout em profissionais da enfermagem e suas complicações no trabalho e na qualidade de vida deles (Moreno, 2011).

\section{Resultados e Discussão}

A pesquisa foi realizada de acordo na base de dados SCIELO e BIREME. Assim, foram encontrados 46 artigos científicos pela SCIELO; 37 pela BIREME; Na seleção, ficaram 25 pela SCIELO; 5 pela BIREME; aplicando os critérios de inclusão e exclusão da pesquisa, totalizando trinta artigos para estudo.

Diante dos materiais citados, após pesquisa concluída com a leitura integral, foram escolhidos 10 artigos para serem revisados bibliograficamente, sendo escolhidos por tratar especificamente de profissionais da enfermagem no enfrentamento da síndrome de Burnout. Desses, 8 foram selecionados da pesquisa na SCIELO; 2 na BIREME para a construção do quadro seguinte que apresenta os resultados da presente pesquisa:

Quadro 1: artigos selecionados para a demonstração dos resultados da pesquisa.

\begin{tabular}{|c|c|c|c|}
\hline Autor/Ano & Objetivo & Método & Resultados \\
\hline $\begin{array}{l}\text { FERREIRA; } \\
\text { MARTINO; } \\
2006\end{array}$ & $\begin{array}{l}\text { Avaliar o estresse do } \\
\text { enfermeiro: análise } \\
\text { das publicações } \\
\text { sobre o tema }\end{array}$ & Revisão de literatura & $\begin{array}{l}\text { Constatou-se o crescente interesse sobre o tema, assim } \\
\text { como um aumento de publicações, porém ainda com } \\
\text { poucas referências específicas dos enfermeiros. } \\
\text { Como sugestão foi apontada: novas pesquisas sobre o } \\
\text { tema, como estudos de caso específicos para a } \\
\text { enfermagem. }\end{array}$ \\
\hline $\begin{array}{l}\text { SILVA; } \text { et al, } \\
2015\end{array}$ & $\begin{array}{l}\text { Investigar Burnout e } \\
\text { estratégias de } \\
\text { enfrentamento em } \\
\text { profissionais de } \\
\text { enfermagem }\end{array}$ & $\begin{array}{l}\text { Estudo de Caso: Aplicaram-se as } \\
\text { escalas MBI, EMEP e uma Ficha } \\
\text { Sociodemográfica em } 193 \\
\text { profissionais. } \\
\text { Efetuaram-se análises } \\
\text { descritivas, de Cluster e o Teste t } \\
\text { de Student. }\end{array}$ & $\begin{array}{l}\text { Os resultados identificaram dois grupos com as } \\
\text { seguintes configurações de burnout: 1) Avançado e 2) } \\
\text { Moderado, em } 47,4 \% \text { e } 36,6 \% \text { da amostra, } \\
\text { respectivamente. }\end{array}$ \\
\hline $\begin{array}{l}\text { NASCIMENT } \\
\mathrm{O}, 2013\end{array}$ & $\begin{array}{l}\text { Analisar a síndrome } \\
\text { de Burnout entre os } \\
\text { profissionais de } \\
\text { enfermagem no } \\
\text { contexto hospitalar }\end{array}$ & $\begin{array}{c}\text { Revisão de literatura: } \\
\text { profissionais de enfermagem que } \\
\text { atuam em ambientes } \\
\text { hospitalares, no período de } 2005 \\
\text { a } 2012\end{array}$ & $\begin{array}{l}\text { Estudos evidenciam que essa Síndrome envolve diversos } \\
\text { fatores não só individuais, como coletivos e laborais, por } \\
\text { isso pode ser considerado multicausal. }\end{array}$ \\
\hline
\end{tabular}




\begin{tabular}{|c|c|c|c|}
\hline $\begin{array}{l}\text { SILVA E } \\
\text { MAXIMINO; } \\
\text { et al, } 2016 \text {. }\end{array}$ & $\begin{array}{l}\text { Avaliar a Síndrome } \\
\text { de Burnout em } \\
\text { Profissionais de } \\
\text { Enfermagem Na UTI }\end{array}$ & $\begin{array}{c}\text { Revisão de literatura: artigos } \\
\text { nacionais publicados no período } \\
\text { de } 2001 \text { a } 2013 .\end{array}$ & $\begin{array}{l}\text { A síndrome é uma experiência individual que prejudica } \\
\text { a relação do indivíduo com seu trabalho, devendo ser } \\
\text { focado na prevenção com a capacitação e discussão } \\
\text { contínua sobre a SB e doenças relacionadas. }\end{array}$ \\
\hline $\begin{array}{l}\text { SANTOS; } e t \\
a l, 2009\end{array}$ & $\begin{array}{l}\text { Analisar a síndrome } \\
\text { de Burnout em } \\
\text { enfermeiros atuantes } \\
\text { em uma Unidade de } \\
\text { Terapia Intensiva }\end{array}$ & $\begin{array}{c}\text { Estudo de caso: A amostra foi } \\
\text { composta por } 34 \text { enfermeiros } \\
\text { que responderam o inventário de } \\
\text { Maslach e Jackson (MBI-HSS). } \\
\text { O estudo foi realizado em um } \\
\text { hospital particular, de grande } \\
\text { porte, localizado em São Paulo. }\end{array}$ & $\begin{array}{l}\text { Dos } 34 \text { enfermeiros, nove apresentaram elevado nível } \\
\text { de desgaste emocional; nove alto nível de } \\
\text { despersonalização e dez apresentaram alto nível de } \\
\text { incompetência profissional, sendo que esses enfermeiros } \\
\text { apresentaram alterações em mais de uma dimensão do } \\
\text { burnout. }\end{array}$ \\
\hline $\begin{array}{l}\text { FRANÇA; } \\
\text { FERRARI, } \\
2011\end{array}$ & $\begin{array}{l}\text { Investigar a } \\
\text { Síndrome de Burnout } \\
\text { e os aspectos sócio- } \\
\text { demográficos em } \\
\text { profissionais de } \\
\text { enfermagem }\end{array}$ & $\begin{array}{l}\text { Estudo de caso: realizado com } \\
141 \text { profissionais de } \\
\text { enfermagem. Utilizado um } \\
\text { questionário estruturado } \\
\text { acrescido do instrumento } \\
\text { Maslach Burnout Inventory } \\
\text { (MBI). }\end{array}$ & $\begin{array}{l}\text { Com base na análise das entrevistas dos } 141 \\
\text { profissionais, } 13(9,58 \%) \text { apresentaram Síndrome de } \\
\text { Burnout, conforme o MBI, e destes acometidos } 7 \\
(53,84 \%) \text { são enfermeiros e } 6 \text { (46,16\%) } \\
\text { técnico/auxiliares. Sugerindo intervenções em relação às } \\
\text { condições de trabalho dos enfermeiros, como terapias } \\
\text { psicossociais e rodas de conversa multiprofissional. }\end{array}$ \\
\hline $\begin{array}{l}\text { SPINDOLA; } \\
\text { MARTINS, } \\
2007\end{array}$ & $\begin{array}{l}\text { Avaliar o estresse na } \\
\text { enfermagem: a } \\
\text { percepção das } \\
\text { auxiliares de } \\
\text { enfermagem de uma } \\
\text { instituição pública }\end{array}$ & $\begin{array}{c}\text { Estudo de caso: Foram } \\
\text { investigadas } 15 \text { trabalhadoras de } \\
\text { um hospital público no } \\
\text { município do Rio de Janeiro. }\end{array}$ & $\begin{array}{l}\text { Evidenciou que o estresse é percebido como um } \\
\text { distúrbio emocional que acarreta desequilíbrio da saúde } \\
\text { mental, ocasionando irritação, mau humor e } \\
\text { incapacidade para o trabalho. Concluiu que embora } \\
\text { definam o estresse como um distúrbio e atuem em } \\
\text { condições desfavoráveis, nem todas percebem a } \\
\text { influência destes fatores no seu equilíbrio emocional. }\end{array}$ \\
\hline $\begin{array}{l}\text { MOREIRA; } e t \\
\text { al,2009 }\end{array}$ & $\begin{array}{l}\text { Investigar } \\
\text { prevalência da } \\
\text { síndrome de burnout } \\
\text { em trabalhadores de } \\
\text { enfermagem de um } \\
\text { hospital de grande } \\
\text { porte da Região Sul } \\
\text { do Brasil }\end{array}$ & $\begin{array}{l}\text { Estudo de caso: foram aplicados } \\
\text { questionários com dados sócio- } \\
\text { culturais e o Maslach Burnout } \\
\text { Inventory em } 151 \text { trabalhadores } \\
\text { do serviço de enfermagem }\end{array}$ & $\begin{array}{l}\text { Foram encontradas pontuações médias em cansaço } \\
\text { emocional }(17) \text {, despersonalização }(7,79) \text { e em } \\
\text { realização pessoal }(36,6) \text {. De acordo com os critérios de } \\
\text { Grunfeld et al., } 35,7 \% \text { dos entrevistados apresentaram } \\
\text { burnout. }\end{array}$ \\
\hline $\begin{array}{l}\text { BATISTA; } \\
\text { BIANCHI, } \\
2006\end{array}$ & $\begin{array}{l}\text { Avaliar o estresse do } \\
\text { enfermeiro em uma } \\
\text { unidade de } \\
\text { emergência }\end{array}$ & $\begin{array}{l}\text { Estudo de caso: determinar o } \\
\text { nível de estresse. Amostra } 73 \\
\text { enfermeiros. Aplicação de } \\
\text { questionários. }\end{array}$ & $\begin{array}{l}\text { Os resultados indicaram que os enfermeiros de unidade } \\
\text { de emergência apresentam médio nível de estresse, } \\
\text { sendo que as condições de trabalho e a administração de } \\
\text { pessoal, são consideradas as áreas mais estressantes para } \\
\text { os indivíduos pesquisados }\end{array}$ \\
\hline $\begin{array}{l}\text { GOMES; } \text { et al, } \\
2006\end{array}$ & $\begin{array}{l}\text { Analisar o } \\
\text { sofrimento psíquico } \\
\text { em trabalhadores } \\
\text { de UTI interferindo } \\
\text { no seu modo de } \\
\text { viver a enfermagem }\end{array}$ & $\begin{array}{l}\text { Estudo de caso: entrevista de } \\
\text { uma enfermeira e sete auxiliares } \\
\text { de enfermagem }\end{array}$ & $\begin{array}{l}\text { Identificaram-se as principais causas do estresse nos } \\
\text { profissionais: rígido controle do tempo; forma como o } \\
\text { setor é organizado; falta de materiais e equipamentos } \\
\text { adequados; conflitos no relacionamento entre os } \\
\text { membros da equipe; estado crítico de saúde do paciente; } \\
\text { dupla jornada de trabalho feminino; e trabalho nos finais } \\
\text { de semana e feriados, o que pode } \\
\text { ocasionar a SB. }\end{array}$ \\
\hline
\end{tabular}

Fonte: Autores.

A partir da revisão desses artigos, denota-se que a síndrome de Burnout é uma evidência na realidade da enfermagem, mesmo que muitos profissionais não se identifiquem dentro desse contexto, haja vista que o alto estresse faz parte do cotidiano dos profissionais de enfermagem. Dessa forma, Ferreira; Martino (2006), ao desenvolverem uma revisão de literatura de avaliação do estresse do enfermeiro, a partir da análise das publicações sobre o tema apresentaram que tem aumentado as pesquisas, denotando interesse e/ou preocupação relacionada às patologias que tem afetado os profissionais de enfermagem, a partir do alto índice de estresse de seu labor. Entretanto, a escassez de material específico sobre a enfermagem é uma realidade.

Por conseguinte, Ferreira; Martino (2006), também apresentaram que os principais fatores causadores de estresse, que podem evoluir para a SB foram a dupla jornada de trabalho, alta responsabilidade, trabalho com pacientes graves, falta de pessoal qualificado e alta demanda de pacientes. Isso pode desencadear o desenvolvimento da SB, e por isso os autores 
dispõem como sugestão a realização de novas pesquisas sobre o tema, como estudos de caso, específicos para a enfermagem, a fim de diagnosticar e tratar os profissionais de forma efetiva e qualitativa.

Silva et al (2015), propuseram um estudo de caso com 193 profissionais da enfermagem, identificando dois grupos com configurações de burnout: 47,4\% avançado e 36,6 \% moderado. Isso significa que mais da metade dos profissionais investigados apresentaram a doença. Assim, a despersonalização se destacou como a dimensão mais afetada do burnout, representando o aspecto interpessoal da síndrome, como uma possível blindagem psíquica inconsciente dos indivíduos para evitar envolvimento afetivo com os pacientes, e que talvez esteja dificultando o enfrentamento aos fatores do estresse hospitalar.

De igual modo, Silva; et al (2015), apontou em seus estudos que nenhuma estratégia de enfrentamento se mostrou suficientemente eficaz no combate aos estressores laborais. Assim, o que pode ser sugerido é a sua prevenção, ou seja, o monitoramento do estresse laboral, de modo que não evolua para a SB. Nascimento (2013), por sua vez, ao analisar a síndrome de Burnout entre os profissionais de enfermagem no contexto hospitalar dispõe que essa Síndrome envolve diversos fatores não só individuais, como coletivos e laborais, por isso pode ser considerado multicausal, e para tanto, sugere que as estratégias para enfrentamento vão desde as terapias psicossociais até qualificação do ambiente laboral com espaço de convivência e rodas de conversa multiprofissionais. Isso foi apontado em uma revisão de literatura com profissionais de enfermagem que atuam em ambientes hospitalares, realizada com material selecionado no período de 2005 a 2012. Assim, confirma que a prevenção do estresse laboral é a melhor das estratégias no enfrentamento da doença por profissionais da enfermagem que estão diretamente vulneráveis à patologia.

Silva; Maximino; et al (2016) avaliou a síndrome de Burnout em Profissionais de Enfermagem especificamente na UTI e mostraram que a síndrome é uma experiência individual que prejudica a relação do indivíduo com seu trabalho, atrapalhando seu desempenho profissional, o que reflete em prejuízos para o indivíduo, para a organização e pode estender-se para o usuário do serviço. Como sugestão, também concluíram que a prevenção é a melhor maneira para que esses profissionais não se tornem alvos da doença e isso pode ser feito com a capacitação e discussão contínua sobre a SB e doenças relacionadas. Santos; et al (2009) também investigou a síndrome de Burnout em enfermeiros atuantes em uma Unidade de Terapia Intensiva em um hospital particular, de grande porte, localizado em São Paulo, apresentando que seja na iniciativa privada ou no serviço público o estresse inerente aos profissionais da enfermagem continua o mesmo, uma vez que grande parte da amostra investigada apresentou Burnout, e houve correlação positiva entre ela e as seguintes variáveis: sexo, especialização na área, tempo de trabalho na área, carga horária, e trabalhar em mais de uma instituição.

De igual modo, Santos; et al (2009) ratifica em seu estudo que dos 34 enfermeiros investigados, nove apresentaram elevado nível de desgaste emocional; nove alto nível de despersonalização e dez apresentaram alto nível de incompetência profissional, sendo que esses enfermeiros apresentaram alterações em mais de uma dimensão do Burnout, denotando uma temática intrinsicamente ligada ao estresse laboral no âmbito da saúde, sendo a UTI um local dentro da assistência hospitalar com grande incidência.

França; Ferrari (2011) apresentou um estudo de caso realizado com 141 profissionais de enfermagem, utilizando um questionário estruturado acrescido do instrumento Maslach Burnout Inventory (MBI), denotando a investigação da Síndrome de Burnout a partir dos aspectos sócio- demográficos em profissionais de enfermagem. Assim, com base na análise das entrevistas dos 141 profissionais, 13 (9,58\%) apresentaram Síndrome de Burnout, conforme o MBI, e destes acometidos 7 (53,84\%) são enfermeiros e 6 (46,16\%) técnico/auxiliares. Quanto à incidência da SB em função dos aspectos sócios demográficos, o maior número de casos foi verificado no sexo feminino, nos profissionais com menos tempo de formação e nos solteiros. Resultados semelhantes foram encontrados na literatura, relevando as constatações. Este estudo evidenciou que a 
presença da SB nos profissionais de enfermagem, revelando assim a necessidade de intervenções em relação às condições de trabalho dos enfermeiros, como terapias psicossociais.

Desse modo, França; Ferrari (2011) reafirma que a SB acomete mais profissionais de enfermagem com as seguintes características sócio- demográficas: sexo feminino, com duplos vínculos; tempo de trabalho na área estressante; carga horária excessiva e/ou contínua; atuantes, principalmente na UTI e PS.

Spindola; Martins (2007) por sua vez, avaliaram o estresse na enfermagem, a percepção das auxiliares de enfermagem de uma instituição pública. Desse modo, comprovou o estudo de Santos; et al (2009), que fez a investigação em um hospital particular, de que a SB é uma realidade entre profissionais da enfermagem nos dois âmbitos. Assim, Spindola; Martins (2007) dispõe que o estresse é percebido como um distúrbio emocional que acarreta desequilíbrio da saúde mental, ocasionando irritação, mau humor e incapacidade para o trabalho. E nesse contexto, as profissionais pesquisadas não se julgam estressadas, embora algumas refiram esta sensação em certas ocasiões, acreditam que a atividade laboral pode contribuir para o estresse pelas condições e características do trabalho que realizam. Para tanto, esse estudo mostrou que, embora definam o estresse como um distúrbio e atuem em condições desfavoráveis, nem todas percebem a influência destes fatores no seu equilíbrio emocional, sendo importante que se valorize a saúde mental dos trabalhadores, especialmente os profissionais de enfermagem, que necessitam estar bem física e mentalmente para interagirem no cuidado com os pacientes.

Batista; Bianchi (2006) já fizeram uma abordagem do estresse dos profissionais de enfermagem em uma unidade de emergência, a fim de determinar o nível de estresse nesse ambiente laboral, com base em 73 profissionais, com a aplicação de questionários. Os resultados indicaram que os enfermeiros de unidade de emergência apresentam médio nível de estresse, sendo que as condições de trabalho e a administração de pessoal foram consideradas as áreas mais estressantes para os indivíduos pesquisados.

Desse modo, de acordo com Batista; Bianchi (2006), para o enfermeiro de emergência, apesar de sua pronta e efetiva atuação frente à instabilidade da situação do paciente, as condições externas a essa situação são mais estressantes, podendo gerar a SB. Como propostas foram apontadas: rodas de conversa; terapias individuais e em grupo; capacitação sobre processos de trabalho.

Gomes; et al (2006) analisou o sofrimento psíquico em trabalhadores de UTI interferindo no seu modo de viver a enfermagem, ou seja, investigou os níveis de estresse, que podem desencadear a SB. Assim, concordaram com os estudos de Spindola; Martins (2007), França; Ferrari (2011) e Santos; et al (2009), quando eles apresentaram que as principais características do estresse nos profissionais da enfermagem são: sexo feminino, dupla jornada; tempo de trabalho na área estressante; carga horária excessiva e/ou contínua; atuantes, principalmente na UTI e PS, bem como acrescentaram ainda, as aspectos de: rígido controle do tempo; forma como o setor é organizado; falta de materiais e equipamentos adequados; conflitos no relacionamento entre os membros da equipe; estado crítico de saúde do paciente, o que pode ocasionar a SB. Como alternativas de enfrentamento foi sugerido: criar espaços para discussões coletivas acerca da gênese do sofrimento psíquico no trabalho, a fim de propiciar o comprometimento dos profissionais com a melhoria da saúde ocupacional e da organização do trabalho.

Moreira; et al (2009), por sua vez, concordou com os estudos de França; Ferrari (2011), realizando a investigação a partir da abordagem dados socioculturais em trabalhadores do serviço de enfermagem, a fim de investigar a prevalência da síndrome de burnout, apresentando pontuações médias em cansaço emocional (17), despersonalização $(7,79)$ e em realização pessoal $(36,6)$, de 151 profissionais pesquisados.

Dessa forma, de acordo com Moreira; et al (2009), com base nos critérios de Grunfeld et al., 35,7\% dos entrevistados apresentaram Burnout. Assim, o perfil padrão do trabalhador com Burnout encontrado pela pesquisa concorda com os estudos de Gomes; et al (2006), Spindola; Martins (2007), França; Ferrari (2011) e Santos; et al (2009), que são profissionais: sexo 
feminino e inerentes a UTI e PS, mas divergem nos quesitos de que são: cargo de técnico de enfermagem, jovens, entre 26 e 35 anos, casados, sem filhos e com mais de cinco anos de profissão. Moreira; et al (2009), ainda concorda com França; Ferrari (2011) no ambiente com maior incidência, ou seja, locais de trabalho que concentraram maior número de trabalhadores com Burnout, apontando os setores agrupados $(42,6 \%)$, a UTI $(25,9 \%)$ e a UTI Neonatal $(18,5 \%)$.

De forma prática, os resultados da pesquisa podem ser demonstrados de acordo com os objetivos específicos da pesquisa, abordando desde o estudo de como a síndrome de Burnout afeta profissionais de enfermagem; o que ela acarreta de prejuízo a esse profissional, no que cabe a sua qualidade de vida, bem como quais ações podem ser feitas pra prevenir e tratar a SB em profissionais da enfermagem.

Para tanto, a partir da revisão dos artigos acima citados, denota-se que a síndrome de Burnout ainda necessita de mais pesquisas, principalmente no que cabe especificamente aos profissionais de enfermagem, que são profissionais intrinsecamente ligados a ambientes e funções de alto estresse laboral.

Nessa perspectiva, de acordo com o objetivo de avaliar como a SB afeta os profissionais de enfermagem, a pesquisa apresentou que os locais com maior incidência são: UTI / UTI Neonatal e Emergência (PS), conforme os estudos de Moreira; et al (2009) e França; Ferrari (2011).

Por conseguinte, as características, ou seja, os aspectos sócio demográficos, as condições e situações desencadeantes da SB são: sexo feminino; dupla jornada; tempo de trabalho na área estressante; carga horária excessiva e/ou contínua; profissionais com menos tempo de formação; solteiros; alta responsabilidade; trabalho com pacientes graves; falta de pessoal qualificado; alta demanda de pacientes, conforme apresentado por Moreira, et al (2009); Gomes et al (2006); Spindola, Martins (2007); França, Ferrari (2011); Santos et al (2009); Ferreira, Martino (2006).

Com relação a esses aspectos, Gomes, et al (2006) divergem dos demais, acrescentando: rígido controle do tempo; desorganização de fluxos; falta de materiais e equipamentos adequados; conflitos interpessoais; estado crítico de saúde do paciente. E ainda, Moreira, et al (2009) acrescenta que são: técnicos em enfermagem; jovens, entre 26 e 35 anos; casados; sem filhos; mais de cinco anos de profissão, divergindo também em alguns aspectos com os demais estudos.

No que compete ao objetivo de verificar o que a SB acarreta de prejuízo a esses profissionais, no que cabe a sua qualidade de vida, os aspectos laborais são: desequilíbrio da saúde mental; irritação; mau humor; incapacidade para o trabalho, segundo França, Ferrari (2011); Spindola, Martins (2007); e Santos, et al (2009).

Com relação aos aspectos socioculturais e psicossociais, são: cansaço emocional; despersonalização; frustração pessoal/laboral/social; sofrimento psíquico; bem como envolve diversos fatores não só individuais, como coletivos e laborais, sendo multicausal, conforme Moreira, et al (2009); França, Ferrari (2011); Spindola, Martins (2007); Santos, et al (2009); Gomes, et al (2006); Nascimento (2013).

Concernente ao objetivo de avaliar quais ações podem ser feitas pra prevenir e tratar a SB em profissionais da enfermagem, as estratégias apontadas foram: rodas de conversa; terapias individuais e em grupo; capacitação sobre os processos e relações no trabalho; terapias psicossociais; qualificação do ambiente laboral com espaço de convivência e rodas de conversa multiprofissional, conforme Batista, Bianchi (2006); Spindola, Martins (2007); Santos, et al (2009); e Nascimento (2013). Já Silva, et al (2015) diverge em seu estudo, dispondo que nenhuma estratégia de enfrentamento se mostrou suficientemente eficaz, devendo, portanto, desenvolver a prevenção, com monitoramento do estresse laboral.

\section{Considerações}

O estudo proposto foi realizado a partir da abordagem e discussão propiciada pela análise da síndrome de Burnout em profissionais de enfermagem, desenvolvendo o estudo de como a síndrome de Burnout afeta profissionais de enfermagem, o 
que ela acarreta de prejuízo a esse profissional, no que cabe desde sua saúde física, até sua qualidade de vida, bem como quais ações podem ser feitas pra prevenir e tratar a síndrome de Burnout em profissionais da enfermagem.

Desse modo, os objetivos traçados para a pesquisa foram atingidos, gerando a agregação de conhecimentos em enfermagem que pode propiciar produção de saber no campo pessoal, profissional e social, a fim de desenvolver ações que viabilizem a melhoria do processo de trabalho, bem como da qualidade de vida desses profissionais em sua prática laboral.

Desse modo, denota-se a importância em compreender as dimensões da saúde do profissional da enfermagem na contemporaneidade, já que a cada dia as demandas aumentam em torno de uma sociedade cada vez mais estressada e o ambiente de trabalho tem sido reflexo dessa rotina social, sendo a área da saúde um processo de trabalho extremamente estressante porque lida com vidas. Nessa perspectiva que a pesquisa mostrou a escassez de material específico sobre a SB em profissionais da enfermagem, carecendo de novas e mais aprofundadas pesquisas sobreo assunto, como estudos de caso, aplicados nos profissionais da enfermagem que atuam tanto no âmbito público quanto privado do Estado do Tocantins, principalmente se considerarmos o contexto atual da pandemia da COVID - 19.

Assim, conclui-se pela compreensão de que a síndrome de Burnout acomete o profissional de enfermagem de modo individual, prejudicando a sua relação com o trabalho e com a equipe, atrapalhando seu desempenho profissional, e refletindo em prejuízos para a instituição, que pode estender-se para o paciente assistido. A patologia é causada por um processo que se dá em resposta ao estresse emocional e interpessoal relativo ao trabalho, com origem nas relações sociais complexas, que envolvem afetivamente profissionais e usuários de um serviço, ou seja, multicausais, necessitando de estratégias de prevenção, como a melhor ação, por meio de terapias, rodas de conversa e discussões no campo laboral.

\section{Referências}

AMB - Revista da Associação Médica Brasileira. A síndrome de Burnout: realidade ou ficção? Rev. Assoc. Med. Bras. https://www.scielosp.org/scielo. php?pid= dx.doi.org/10.1590/S0104-42302007000100004.

Batista, K. M. \& Bianchi, E. R. F. (2006). Estresse do enfermeiro em unidade de emergência. Rev Latino-Am Enfermagem [Biblioteca Virtual de Saúde BIREME].14:534-9. http://regional.bvsalud.org/php/index.php.

Batista, J. B. V., et al. (2009). Prevalência da Síndrome de Burnout e fatores sociodemográficos e laborais em professores e enfermeiros na cidade de João Pessoa, PB. Cadernos de Saúde Pública.. https://www.scielosp.org/scielo. php?pid=S1415-790X2010000300013\&script=sci_arttext.

Camelo, S. H. H., \& Angerami, E. L. S. Riscos psicossociais relacionados ao trabalho das equipes de saúde da família: percepções dos profissionais. Rev enferm UERJ 15:502-7. https://www.scielosp.org/scielo. php?pid=S1415-790X2010000300013\&script=sci_arttext.

Carlos. C.; \& Gadelha. N. (2011). Síndrome de Burnout: Exaustão emocional na saúde. Fonte: Jornal do Comércio. Assessoria de imprensa do Simepe, Recife, 2011. https://www.scielosp.org/scielo. php?pid=S1415- 790X2010000300013\&script=sci_arttext.

Carlotto, M. S. \& Palazzo, L. S. (20009). Síndrome de burnout e fatores associados: um estudo epidemiológico com professores e enfermeiros. Cadernos de Saúde Pública. 2009. https://www.scielosp.org/scielo.php?pid=S0102- 311X2006000500014\& script=sci_art.

Carlotto, M. S. \& Câmara, S. G. (2009). Análise da produção científica sobre a Síndrome de Burnout no Brasil. Psico-PUCRS 2009; 39(2): 152-8. https://www.scielosp. org/scielo.php?pid=S0102-\&script=sci_art.

Ferreira, R. L. C. \& Martino, M. M. F. (2009). O estresse do enfermeiro: análise das publicações sobre o tema. Rev Cienc Med [Periódicos Eletrônicos de Psicologia]. 15(3):241-8. http://www.scielosp. org/scielo.php?pid=S0102- \&script=sci_art.

Fernandes, J. D., et al. (2009). Saúde mental e trabalho: significados e limites de modelos teóricos. Rev Latino-Am Enfermagem. [Biblioteca Virtual de Saúde - BIREME].14:803-1. Disponível em: http://regional.bvsalud.org/php/index.php.

Ferrari. J. S. Síndrome de Burnout. 2013. Brasilescola . https://www.scielosp.org/scielo. php?pid=S1415-790X2010000300013\&script=sci_arttext

Fleury, M. (2010). A informação como estratégia de prevenção da Sindrome de Burnout.. Acta paul.psico. isponível em: https://www.scielosp.org/scielo. php?pid=S1415- 790X2010000300013\&script=sci_arttext.

França, F. M; \& Ferrari, R. (2011). Síndrome de Burnout e os aspectos sócio- demográficos em profissionais de enfermagem. Acta paul. enferm. 25: http://www.scielo.br/scielo. php?script=sci_arttext\&pid=S010321002012000500015 \&lng=en\&nrm=iso

Frazão. A. (2012). Tratamento para a Síndrome de Burnout.Tua saude. https://www.scielosp.org/scielo. php?pid=S1415- 790X2010000300013\&script=sci_ arttext. 
Gomes, G. C. Lunardi Filho W. D. \& Erdmann, A. L. (2009). O sofrimento psiquico em trabalhadores de UTI interferindo no seu modo de viver a enfermagem. Rev enferm UERJ. 14:803-1.

Kovaleski, D. F; \& Bressan, A. (2012). A síndrome de Burnout em profissionais de saúde. Rev. Saúde e Transformação Social. 3.

Mariano, M. S. S. \& Muniz, H. P (2009). Trabalho docente e saúde: o caso dos professores e dos enfermeiros. Estudos e Pesquisas em Enfermagem. 6(1): 7688. Rev Latino-Am Enfermagem. 14:803-1. http://regional.bvsalud.org/php/index.php.

Menezes, V. A. (2015). Contribuição da psicologia clínica na compreensão do Burnout: um estudo com professores e enfermeiros. [Tese de Doutorado]. Brasília: Instituto de Psicologia da UnB; 2015. https://www.scielosp.org/scielo. php?pid=S1415- 790X2010000300013\&script=sci_arttext. set/2019.

Moreira, D. S. et al. (2009). Prevalência da síndrome de burnout em trabalhadores de enfermagem de um hospital de grande porte da Região Sul do Brasil. Rio de Janeiro: Cad. Saúde Pública; https://www.scielosp.org/scielo. php?pid=S1415- 790X2010000300013\&script=sci_arttext.

Moreno, et al. (2011). Estratégias e intervenções no enfrentamento da síndrome de burnout. Rev. enferm. UERJ, 19(1):140-5. http://www.scielosp. org/scielo.php?pid=S0102- \&script=sci_art.dx.doi.org/10.1590/S0104- 42302007000100004.

Nascimento, M. S. (2013). Síndrome de Burnout entre os profissionais de enfermagem no contexto hospitalar [Monografia].

https://www. scielosp.org/scielo.php?pid=

Santos, F. E. Alves, J. A. \& Rodrigues, A. B. (2009). Síndrome de Burnout em enfermeiros atuantes em uma Unidade de Terapia Intensiva. São Paulo: Einstein. Rev. enferm. UERJ. https://www. scielosp.org/scielo.php?pid=

Santos, N. S. M (2005). Quando os dados oficiais revelam condições de trabalho: análise dos agravos à saúde de professores e enfermeiros do Município de São Paulo [tese de doutorado]. https://www. scielosp.org/scielo.php?pid=

Santana, V. S. (2009). Saúde do trabalhador no Brasil: pesquisa na pós-graduação. Rev Saúde Pública. 2009. https://www.scielosp.org/scielo.php?pid= S1415- 790X2010000300013\&script=sci_arttext.

Silva, et al. (2015). Burnout e estratégias de enfrentamento em profissionais de enfermagem. versão On-line ISSN 1809-5267. Arq. bras. psicol. vol.67 no.1 http://www.scielosp. org/scielo.php?pid=S0102- \&script=sci_art.dx.doi.org/10.1590/S0104- 42302007000100004. Acesso em: 16 set/2019.

Silva E Maximino et al. (2016). Síndrome De Burnout Em Profissionais De Enfermagem Na Unidade De Terapia Intensiva. Rev. Ciênc. Saúde Nova Esperança 14(1):79-86. https://www. scielosp.org/scielo.php?pid=

Silva, A. T. C; \& Menezes, P. R. (2009). Esgotamento profissional e transtornos mentais comuns em agentes comunitários de saúde. Rev Saúde Pública 42:921-9.

Silva. S. B. F. (2010). Síndrome De Burnout: Consequência Depressiva Desencadeada Pelo Estresse No Trabalho. Antigonal.

Spindola T, \& Martins, E. R. C. (2007). O estresse e a enfermagem: a percepção das auxiliares de enfermagem de uma instituição pública. Esc Anna Nery [Scielo- Scientific Electronic Library Online]. Rev. enferm. UERJ. https://www. scielosp.org/scielo.php?pid=

Szklar, COL. A Síndrome de Burnout em profissionais da área de saúde. (2011). Rev. esc. enferm.

Trindade, L. L.; \& Laurtett, L. (2010). Síndrome de Burnout entre os trabalhadores da Estratégia de Saúde da Família. Rev. esc. enferm. USP, 44<http://www.scielo. br/ scielo. php?script=sci_arttext\&pid=S0080-6234201000020000 5\&lng=en\&nrm=iso>

Viana. R. A. P. (2009). Síndrome de Burnout em profissionais de terapia intensiva, esse problema é seu. Rev Latino-Am Enfermagem. [Biblioteca Virtual de Saúde-BIREME] 